\title{
healthcareCOVID: A national cross-sectional observational study identifying risk factors for developing suspected or confirmed COVID-19 in UK healthcare workers
}

\author{
Justin Kua ${ }^{\text {Corresp. } 1,2}{ }^{1}$, Reshma Patel ${ }^{1,2}$, Eveliina Nurmi ${ }^{3}$, Sarah Tian ${ }^{4}$, Harpreet Gill ${ }^{4}$, Danny J N Wong ${ }^{2,4}$, Calvin \\ Moorley $^{5}$, Dmitri Nepogodiev ${ }^{6}$, Imran Ahmad ${ }^{4,7}$, Kariem El-Boghdadly ${ }^{4,7}$ \\ ${ }^{1}$ Department of Targeted Intervention, Centre for Perioperative Medicine, UCL Division of Surgery and Interventional Science, University College London, \\ University of London, London, United Kingdom \\ 2 Health Services Research Centre, National Institute of Academic Anaesthesia, Royal College of Anaesthetists, London, United Kingdom \\ 3 Department of Anaesthesia, University College London Hospitals NHS Foundation Trust, London, United Kingdom \\ 4 Department of Anaesthesia, Guy's and St Thomas' NHS Foundation Trust, London, United Kingdom \\ 5 School of Health and Social Care/Adult Nursing \& Midwifery Studies, London South Bank University, London, United Kingdom \\ 6 National Institute for Health Research Global Health Research Unit on Global Surgery, University of Birmingham, Birmingham, United Kingdom \\ 7 King's College London, University of London, London, United Kingdom \\ Corresponding Author: Justin Kua \\ Email address: justin.kua.20@ucl.ac.uk
}

Objective. To establish the prevalence, risk factors and implications of suspected or confirmed coronavirus disease 2019 (COVID-19) infection among healthcare workers in the United Kingdom (UK).

Design. Cross-sectional observational study.

Setting. UK-based primary and secondary care.

Participants. Healthcare workers aged $\geq 18$ years working between 1 February and 25 May 2020.

Main outcome measures. A composite endpoint of laboratory-confirmed diagnosis of SARS-CoV-2, or self-isolation or hospitalisation due to suspected or confirmed COVID-19.

Results. Of 6152 eligible responses, the composite endpoint was present in 1806 (29.4\%) healthcare workers, of whom 49 (0.8\%) were hospitalised, 459 (7.5\%) tested positive for SARS-CoV-2, and 1776 (28.9\%) reported self-isolation. Overall, between 11,870 and 21,158 days of self-isolation were required by the cohort, equalling approximately 71 to 127 working days lost per 1000 working days. The strongest risk factor associated with the presence of the primary composite endpoint was increasing frequency of contact with suspected or confirmed COVID-19 cases without adequate personal protective equipment (PPE): "Never" (reference), "Rarely" (adjusted odds ratio 1.06, (95\% confidence interval: 0.87 to 1.29)), "Sometimes" (1.7 (1.37 to 2.10)), "Often" (1.84 (1.28 to 2.63)), "Always" (2.93, (1.75 to 5.06)).

Additionally, several comorbidities (cancer, respiratory disease, and obesity); working in a 'doctors' role; using public transportation for work; regular contact with suspected or confirmed COVID-19 patients; and lack of PPE were also associated with the presence of the primary endpoint. $1382(22.5 \%)$ healthcare workers reported lacking access to PPE items while having clinical contact with suspected or confirmed COVID-19 cases

Conclusions. Suspected or confirmed COVID-19 was more common in healthcare workers than in the 
general population and is associated with significant workforce implications. Risk factors included inadequate PPE, which was reported by nearly a quarter of healthcare workers. Governments and policymakers must ensure adequate PPE is available as well as developing strategies to mitigate risk for high-risk healthcare workers during future COVID-19 waves. 
1 healthcareCOVID: A national cross-sectional

2 observational study identifying risk factors for

3 developing suspected or confirmed COVID-19

4 in UK healthcare workers

5 Justin Kua ${ }^{1,2}$, Reshma Patel ${ }^{1,2}$, Eveliina Nurmi ${ }^{3}$, Sarah Tian ${ }^{4}$, Harpreet Gill ${ }^{4}$, Danny Jon Nian

6 Wong $^{2,4}$, Calvin Moorley ${ }^{5}$, Dmitri Nepogodiev 6 , Imran Ahmad ${ }^{4,7}$, Kariem El-Boghdadly,7

${ }^{1}$ Department of Targeted Intervention, Centre for Perioperative Medicine, UCL Division of Surgery and Interventional Science, UCL, London, UK

${ }^{2}$ Health Services Research Centre, National Institute of Academic Anaesthesia, Royal College of Anaesthetists, London, UK

${ }^{3}$ Department of Anaesthesia, University College London Hospitals NHS Foundation Trust, London, UK

${ }^{4}$ Department of Anaesthesia, Guy's and St Thomas' NHS Foundation Trust, London, UK

${ }^{5}$ School of Health and Social Care/Adult Nursing \& Midwifery Studies, London South Bank University, London, UK

${ }^{6}$ National Institute for Health Research Global Health Research Unit on Global Surgery, University of Birmingham, Birmingham, UK

${ }^{7}$ King's College London, London, UK

Corresponding author:

Justin Kua

Department of Targeted Intervention, Centre for Perioperative Medicine, UCL Division of

Surgery and Interventional Science, UCL, London, UK

Email address: justin.kua.20@ucl.ac.uk 


\section{Abstract}

Objective. To establish the prevalence, risk factors and implications of suspected or confirmed coronavirus disease 2019 (COVID-19) infection among healthcare workers in the United Kingdom (UK).

Design. Cross-sectional observational study.

Setting. UK-based primary and secondary care.

Participants. Healthcare workers aged $\geq 18$ years working between 1 February and 25 May 2020.

Main outcome measures. A composite endpoint of laboratory-confirmed diagnosis of SARSCoV-2, or self-isolation or hospitalisation due to suspected or confirmed COVID-19.

Results. Of 6152 eligible responses, the composite endpoint was present in 1806 (29.4\%) healthcare workers, of whom $49(0.8 \%)$ were hospitalised, 459 (7.5\%) tested positive for SARSCoV-2, and 1776 (28.9\%) reported self-isolation. Overall, between 11,870 and 21,158 days of self-isolation were required by the cohort, equalling approximately 71 to 127 working days lost per 1000 working days. The strongest risk factor associated with the presence of the primary composite endpoint was increasing frequency of contact with suspected or confirmed COVID-19 cases without adequate personal protective equipment (PPE): "Never" (reference), "Rarely" (adjusted odds ratio 1.06, (95\% confidence interval: 0.87 to 1.29$))$, "Sometimes" (1.7 (1.37 to $2.10))$, "Often" (1.84 (1.28 to 2.63)), "Always" (2.93, (1.75 to 5.06)). Additionally, several comorbidities (cancer, respiratory disease, and obesity); working in a 'doctors' role; using public transportation for work; regular contact with suspected or confirmed COVID-19 patients; and lack of PPE were also associated with the presence of the primary endpoint. $1382(22.5 \%)$ 
51 healthcare workers reported lacking access to PPE items while having clinical contact with

52 suspected or confirmed COVID-19 cases.

53 Conclusions. Suspected or confirmed COVID-19 was more common in healthcare workers than

54 in the general population and is associated with significant workforce implications. Risk factors

55 included inadequate PPE, which was reported by nearly a quarter of healthcare workers.

56 Governments and policymakers must ensure adequate PPE is available as well as developing

57 strategies to mitigate risk for high-risk healthcare workers during future COVID-19 waves.

\section{Introduction}

59 Coronavirus disease 2019 (COVID-19), caused by severe acute respiratory syndrome

60

61

62 coronavirus 2 (SARS-CoV-2), has resulted in a global health crisis that has challenged healthcare systems around the world. As of 11 October 2020, there are over 37 million confirmed cases and at least 1 million deaths worldwide.(World Health Organization) Healthcare workers have been identified to be at risk of nosocomial COVID-19 infection.(Kursumovic, Lennane \& Cook, 2020; El-Boghdadly et al., 2020; Pollán et al., 2020; Shields et al., 2020) In the United States (US), over 177,000 healthcare workers have been infected with COVID-19,(CDC, 2020) and up to $16 \%-17.2 \%$ of those infected in the UK were thought to be key workers, a category that includes both healthcare workers as well as other essential workers from other industries.(Heneghan, Oke \& Jefferson, 2020; Shah et al., 2020)

The prevalence of COVID-19 in healthcare workers is thought to be higher than in the general population, potentially due to exposure to higher viral loads from increased contact with infected individuals.(Heneghan, Brassey \& Jefferson, 2020; Wilson et al., 2020; El-Boghdadly et al., 
73 2020) Prevalence estimates are variable with limited data comparing different staff roles and

74 workplace environments (i.e. secondary versus primary care).(Office for National Statistics;

75 Keeley et al., 2020; Hunter et al., 2020; Nguyen et al., 2020; Shields et al., 2020) This, combined

76 with the limited availability of testing for healthcare workers during early phases of the

77 pandemic, resulted in reliance on periods of self-isolation as a means of controlling the spread of

78 the virus.(Dunn et al.) The impact of self-isolation on the UK healthcare workforce during the

79 height of the pandemic has not been characterised.

80

Recent reports of healthcare workers deaths have also revealed that Black, Asian and Minority

Ethnic (BAME) groups appear to represent a greater proportion of these deaths.(Kursumovic,

Lennane \& Cook, 2020) The reasons for this preponderance of BAME groups and COVID-19 severity in healthcare workers as well as the general population are likely to be complex and multifactorial.(Intensive Care National Audit \& Research Centre, 2020; Aldridge et al., 2020; Kursumovic, Lennane \& Cook, 2020) Similarly, healthcare workers-related mortality from COVID-19 in the UK is reported as one of the highest globally, yet the reasons for this are poorly understood.(Amnesty Internaional UK)

Given the potential for aerosol transmission of SARS-CoV-2, healthcare workers exposed to aerosol-generating procedures (AGPs) are at potentially higher risk of developing COVID19.(Cook, 2020; Wilson et al., 2020; El-Boghdadly et al., 2020) However, what constitutes an AGP remains contentious, with conflicting international and national guidance.(Public Health England; World Health Organization) Furthermore, shortages of personal protective equipment 95 (PPE) throughout the pandemic and beyond remain a concern for healthcare workers.(The 
96 Lancet, 2020) Taken together, the workplace environmental risks for healthcare workers with

97 different exposures to COVID-19 and access to PPE remain unclear, particularly in the early

98 surges of the pandemic.

99

We therefore designed a UK-wide cross-sectional study to understand the prevalence and possible risk factors for the reporting of suspected or confirmed COVID-19 infection amongst healthcare workers. We also sought to estimate access to testing and the number of working days lost from self-isolation. Finally, we aimed to capture details on socio-demographics, occupational exposure, and use of PPE to help expand the evidence base for healthcare workers and policymakers.

\section{6}

\section{Materials and Methods}

We conducted a cross-sectional observational study of UK-based healthcare workers between 4-

25 May 2020 in England, Northern Ireland, Scotland and Wales. We included all healthcare workers aged 18 years or above and working at any time since 1 February 2020. Healthcare workers practicing in both primary (community and social care facilities) as well as secondary (hospitals) care were eligible. The study was prospectively registered as a service evaluation project at Guy's and St Thomas' NHS Foundation Trust (Service Evaluation ID: 10834) and was

113 deemed to not require ethical approval by the Research and Development Department and the Health Research Authority Decision Tool. 
117 We designed an online survey using Knack (Evenly Odd Inc., Philadelphia, USA), an online data

118 capture and database system. A multi-phased process involving several authors (JK, RP, KE, IA,

119 DW, CM) was used to construct, revise and ratify the final survey. An initial draft of questions

120 for the survey was created by JK and RP and sent to the remaining authors for review. Based on

121 feedback received, modifications were made and questions compiled, followed by a second

122 round of review and testing by all authors on the online system. This version of the survey was

123 piloted in a convenience sample of 93 participants. One change was made as a consequence: an

124 expanded list of specialties was implemented.

125

126 The final survey comprised 33 closed questions and five free-text entries, divided into five

127 sections: (1) participant characteristics; (2) work details; (3) self-isolation and COVID-19 status;

128 (4) workplace exposure characteristics; and (5) PPE (supplementary material). Free-text entries

129 were used for gender identity (if not the same as sex at birth), ethnic background (if not within

130 one of the listed groups), number of days of self-isolation (if greater than 14 days, with

131 conditional limits) and an 'Other Comments' question. The survey covered experiences from the

132 period 1 February 2020 to the date when each healthcare workers participated in the study.

134 Survey administration

135 The survey was disseminated electronically using a web link which directed potential

136 participants to the survey form. This web link was shared on several relevant social media

137 platforms and via e-mail. We engaged several organisations and Royal Colleges to assist with

138 dissemination to their respective membership, which included the Association for Perioperative

139 Practice, the COVID-19 Information Hub for the Royal College of Surgeons of England, the 
140 Royal College of Occupational Therapists, and the Association of Anatomical Pathology

141 Technology.

142

143 Definitions

144 Several survey response variables were grouped a priori to facilitate analyses. We defined a

145 collective 'BAME' ethnic group as those participants who identified as 'Asian or Asian British',

146 'Black, African, Black British or Caribbean', 'Mixed or multiple ethnic groups', and 'another

147 ethnic group', in keeping with contemporary reporting.(Intensive Care National Audit \&

148 Research Centre, 2020; Aldridge et al., 2020; Kursumovic, Lennane \& Cook, 2020)

149 Occupational roles were grouped into five subgroups: (1) Doctors - all doctors; (2) Dentists and

150 dental staff - dentist, dental nurse, and dental hygienist; (3) Nurses, midwives and associated

151 staff - healthcare assistant, maternity care worker, midwife, nurse, and nursing associate; (4)

152 Allied Health Professionals (AHPs) - dietician, healthcare scientist (e.g. lab-based), occupational

153 therapist, operating department practitioner, optician, paramedic, pharmacist, phlebotomist,

154 physician associate, physiotherapist, psychologist, radiographer, speech and language therapist,

155 technician (clinical), and therapist (Other); and (5) Other - administrative staff, domestic

156 services, manager (care home), 'other', porter, senior carer (care home), support

157 worker/assistant, and wellbeing/activity coordinator (care home). In line with Public Health

158 England (PHE) guidance,(Public Health England) higher risk areas were considered to be the

159 following: COVID-19 pod/bay/ward, day case surgery unit, emergency department (ED),

160 endoscopy unit (upper respiratory, ENT or upper GI endoscopy), intensive care (ICU)/High

161 dependency unit (HDU), and operating theatre. 
163 We originally included an option for "Intersex" when enquiring about sex and gender identity to

164 support inclusivity based on published guidance.(Reisner et al., 2014; Spiel, Haimson \&

165 Lottridge, 2019) However, during the study, several healthcare workers and members of the

166 public expressed concern regarding this approach, leading to a removal of the option for

167 "Intersex", leaving only "Male" and "Female" as options for sexual identity. We retained the

168 question about gender identity, including a free-text option for those who identified as a gender 169 not the same as sex at birth.

171 The primary endpoint of this study was a composite outcome of any of the following: (1) self-

172 isolation due to COVID-19 symptoms or a positive SARS-CoV-2 test, (2) hospitalisation with 173 suspected or confirmed COVID-19 and (3) laboratory-confirmed SARS-CoV-2 infection (via 174 reverse transcription polymerase chain reaction or antibody testing).

Data analysis

177 We report our findings according to STrengthening the Reporting of OBservational studies in Epidemiology (STROBE) guidance (supplementary material).(STROBE Group)

Statistical analyses were conducted in R Version 4.0.2 (The R Foundation for Statistical

181 Computing, Vienna, Austria). Code for all analyses is available as supplementary material.

182 Continuous data are reported using mean (standard deviation, SD) or median (interquartile 183 ranges, IQR) where appropriate for measures of central tendency and spread. Categorical data

184 are reported as numbers (percentages, \%). A $p$-value $<0.05$ was considered statistically

185 significant. Relationships between categorical variables and outcome measures are presented as 
186 univariate odds ratios with accompanying $p$-values (Pearson's Chi-square test with Yates'

187 continuity correction). A planned analysis of free-text entries in "Other Comments" will be 188 reported in a separate paper.

To identify risk factors for COVID-19 amongst healthcare workers, we modelled the association between covariates chosen a priori and the COVID-19 composite endpoint using univariable and multivariable logistic regression modelling. Covariates included in the multivariable model were: age, sex, ethnicity, household composition, country of residence, main healthcare facility of work, employment role group, use of public transport to travel to work, regularity of clinical contact with suspected or confirmed COVID-19 patients, regularity of exposure to AGP(s) performed in suspected or confirmed COVID-19 patients, whether the participant had sufficient training in PPE use, whether the participant lacked access to PPE items for clinical contact with suspected or confirmed COVID-19 patients, degree of clinical contact with patients without adequate PPE, whether the participant reused disposable PPE, and whether the participant used improvised PPE. As questions on comorbidities and tobacco smoking were optional in the survey, those participants who did not answer these questions were identified as "Prefer not to say". For those participants who answered "No" to regular clinical contact with suspected or confirmed COVID-19 cases without adequate PPE, they were regarded as having a frequency of "None" for clinical contact without adequate PPE. Findings from the regression analysis are reported as adjusted odds ratios (OR) with 95\% confidence intervals (95\% CI) and accompanying $p$-values. Quality of the final model was assessed by the Akaike information criterion (AIC) and Area Under the Receiver Operating Characteristic curve (AUROC). 
209 Three further post hoc analyses were conducted to test the robustness of our findings:

210

211

212

213

214

215

216

217

218

219

220

221

222

223

224

225

226

227

228

229

230

(1) modelling was repeated in a subgroup of participants who had regular clinical contact with suspected or confirmed COVID-19 patients. This was done to test if certain workplace environments exposed participants to a greater risk of SARS-CoV-2 infection. (2) modelling was repeated in a subgroup reporting regular exposure to AGPs conducted in suspected or confirmed COVID-19 patients. This was done to assess if participant exposure to certain AGPs were more likely to result in infection with SARS-CoV-2.

(3) a separate multivariable model was constructed using a more conservative dependent outcome variable of laboratory-confirmed SARS-CoV-2 infection, adjusting for the same covariates as in the full model above. This was done to limit the outcome to only laboratory-confirmed cases of SARS-CoV-2, thereby reducing bias from suspected cases (e.g. those who self-isolated but were never tested).

\section{Patient and Public Involvement}

As the survey was designed by healthcare workers, and the target population was healthcare workers, patient and public involvement was not sought.

\section{Results}

The study was conducted between 4-25 May 2020, and a total of 6260 participants responded, with 6152 eligible for analysis (Figure 1).

\section{Participant characteristics}

Participant characteristics for the sampled population are summarised in Table 1. 
232 Work details

233 A total of 5518 participants were healthcare workers based in England (89.7\%), followed by 321

$234(5.2 \%)$ in Scotland, $213(3.5 \%)$ in Wales and $100(1.6 \%)$ in Northern Ireland. Based on region,

$2351770(28.8 \%)$ responses were received from Greater London, with all other regions contributing

236 less $5.5 \%$ each. Figure 2 shows responses stratified by main healthcare facility. Healthcare

237 worker roles were grouped into doctors $(1770(28.8 \%))$, nurses, midwives and associated staff

$238(2516(40.9 \%))$, dentists and dental staff (198 (3.2\%)), AHPs (1118 (18.2\%)), and Other (550

$239(8.9 \%))$. eTables 1 to 4 summarises responses into healthcare workers roles and grades

240 (supplementary material).

242 A total of 3902 (63.4\%) healthcare workers reported regular clinical contact with suspected or

243 confirmed COVID-19 patients. Of all participants, 2296 (37.3\%) responded as having had

244 regular exposure to AGPs performed in suspected or confirmed COVID-19 patients. Data for

245 areas of clinical contact and the AGPs that participants were exposed to are summarised in

246 eFigure 1 and eFigure2, respectively (supplementary material).

248 COVID-19 status

249 A total of 1776 participants (28.9\%) self-isolated because of COVID-19 symptoms (eFigure 3, 250 supplementary material) or testing positive for SARS-CoV-2. Of those who self-isolated, 840

251 (47.3\%) self-isolated for 1-7 days, 708 (39.9\%) for 8-14 days, and 228 (12.8\%) for more than 14

252 days. The total number of days of self-isolation in this cohort was between 11,870 and 21,158

253 days. The mean (SD) duration of self-isolation for participants who self-isolated for more than 
25414 days was 23.4 (8.8) days. In addition, 228 participants (12.8\%) self-isolated more than once.

255 Forty-nine (0.8\%) participants were hospitalised for suspected or confirmed COVID-19.

256 Responses for testing for SARS-CoV-2 revealed a total of 1407 (22.9\%) participants who were

257 tested during the period covered by the survey: $948(15.4 \%)$ had never tested positive or were

258 awaiting test results, $20(0.3 \%)$ were positive on blood testing and $439(7.1 \%)$ were positive on

259 oral/nasal swab testing.

260

261

Personal Protective Equipment

262 With regards to PPE, 4334 (70.4\%) participants answered that they had received sufficient

263 training in the use of PPE. Throughout the timeframe of interest, $1382(22.5 \%)$ participants had

264 been in a situation where they lacked access to items of PPE when having clinical contact with

265 suspected or confirmed COVID-19 patients. Figure 3 summarises the PPE items that participants

266 reported lack of access to under these situations. Furthermore, 1306 (21.2\%) participants had

267 been in clinical contact with suspected or confirmed COVID-19 patients without adequate PPE.

268 The top three reasons for these encounters without adequate PPE were 'Patient not

269 suspected/confirmed', 'Lack of PPE availability', and 'Senior instruction' (summarised in

270 eFigure 4 of supplementary material).

271

272 Univariable and multivariable modelling against the COVID-19 composite

273 The results from univariable and multivariable analyses of covariates from the survey and the

274 presence of the COVID-19 composite endpoint are summarised in Table 2 and eTable 5

275 (supplementary material).

276

Peer] reviewing PDF | (2020:10:54534:1:2:NEW 26 Dec 2020) 
277 No difference in the presence of the COVID-19 composite endpoint was seen between different

278 ethnic groups. This persisted with constituent ethnic groups replacing the collective BAME

279 group: Asian or Asian British (adjusted OR 0.96 (0.81 - 1.14), p-value = 0.643), Black, African,

280 Black British or Caribbean (adjusted OR 1.03 (0.79 - 1.33), $p$-value = 0.845), Mixed or Multiple

281 ethnic groups (adjusted OR $0.99(0.69-1.40), p$-value $=0.937)$, and Another ethnic group

282 (adjusted OR $0.96(0.67-1.36), p$-value $=0.828)($ eTable 6, supplementary material $)$.

283

284 Being a current or ex-smoker (within 1 year) was associated with a significant decrease in odds

285 for the COVID-19 composite endpoint compared to participants who never smoked. To assess if

286 this effect was due to collider bias following adjustments for comorbidities in our model, an

287 additional model was constructed with comorbidities removed (eTable 7, supplementary

288 material). However, in this model, being a current or ex-smoker (within 1 year) still had reduced

289 odds for the presence of the composite endpoint (adjusted OR $0.79(0.64-0.98), p$-value $=$

290 0.034).

291

292 Post hoc analyses

293 In a subgroup of participants who had regular clinical contact with suspected or confirmed

294 COVID-19 patients (3902 (63\%)), those working in higher risk areas as defined by PHE ${ }^{15}$ made

295 up 81.7\%. Working in an inpatient clinic area was associated with a significant increased risk of

296 reporting the primary endpoint (adjusted OR $1.41(1.01-1.97), p=0.043)$. The following areas

297 were associated with a significant decreased risk: home visits (adjusted OR $0.68(0.47-0.98), p$

$298=0.040)$, ICU/HDU (adjusted OR $0.78(0.65-0.94), p=0.007)$, operating theatre (adjusted OR

$2990.71(0.57-0.87), p=0.001)$, radiology (adjusted OR $0.62(0.42-0.91), p=0.016)$ and other 
300

301

302

303

304

305

306

307

308

309

310

311

312

313

314

315

316

317

318

319

320

321

areas (adjusted OR $0.69(0.48-0.98), p=0.044)$. eTable 8 (supplementary material)

summarises the model for this subgroup analysis.

In terms of exposure to AGPs, a second subgroup analysis of participants who had been regularly exposed to AGPs used in suspected or confirmed COVID-19 patients (2296 (37.3\%)) showed that $95.8 \%$ of this cohort were exposed to procedures considered by PHE to be AGPs ${ }^{18}$ (i.e. this excludes 'CPR', 'nebulisers' and 'other' as AGPs during the study period). In this subgroup, no particular AGP was associated with a significant change in risk on multivariate analysis (eTable 9, supplementary material).

Finally, an additional multivariable regression model constructed using a more restrictive outcome of laboratory-confirmed SARS-CoV-2 (eTable 10, supplementary material). In this additional model, the associations between the outcome and the following factors remained significant, adjusting for other covariates: regular clinical contact with COVID-19 patients, regular exposure to AGP(s) performed in COVID-19 patients, lack of access to PPE items for clinical contact with COVID-19 patients, clinical contact without adequate PPE, and use of improvised PPE.

\section{Discussion}

Principal Findings

We describe the characteristics of a sample of UK-based healthcare workers working during the COVID-19 pandemic and relate their experiences to the development of COVID-19 infectionrelated outcomes. The overall prevalence of the primary composite endpoint amongst healthcare 
322 workers was $29.4 \%$ over the period from $1^{\text {st }}$ February to $25^{\text {th }}$ May 2020 . We report a substantial

323 number of working days lost from self-isolation due to symptoms and estimate between 11,800

324 and 21,100 working days lost during the study period, translating to between 71 to 127 working

325 days lost per 1000 working days (assuming a 40-hour work week per healthcare workers). Under

326 a quarter of participants were tested for SARS-CoV-2 throughout the period. Additionally, a

327 number of risk factors were explored using regression modelling of the survey responses.

328 Finally, we report that $22.5 \%$ of participants had encountered a situation where they lacked PPE

329 items and identified a variety of PPE items that were not available.

330

331

Interpretation in the context of wider literature

332 The prevalence of suspected or confirmed COVID-19 amongst healthcare workers is higher in 333 our sampled population compared to other sources.(Office for National Statistics; Keeley et al., 2020; Hunter et al., 2020; El-Boghdadly et al., 2020; Pollán et al., 2020) Previous estimates have ranged from as low as $1.73 \%$ through a population survey-based approach(Office for National Statistics) to as high as between 7.7 - $24.4 \%$ via testing of healthcare staff.(Keeley et al., 2020; Hunter et al., 2020; Pollán et al., 2020; Shields et al., 2020) A study amongst healthcare workers involved in tracheal intubation using a similar primary endpoint reported an overall incidence of $10.7 \%$ over a median follow-up period of 32 days.(El-Boghdadly et al., 2020) The use of a composite endpoint facilitated capture of outcomes from individuals who were plausibly at risk of testing positive for SARS-CoV-2, but who were never tested. Indeed, $77.2 \%$ of our total sampled population $(n=4745)$ had never been tested. During the time period, healthcare workers had to self-isolate based on clinical symptoms alone due to lack of mass testing.(Dunn et al.)

344 Over three quarters of our study cohort were not tested for SARS-CoV-2. Consequently, a 
345 substantial number of working days were lost as workers had to self-isolate for prespecified

346 durations, rather than potentially testing negative for the virus and returning to work earlier.

347 Drawing definitive prevalence conclusions from the data reported herein is challenging due to

348 the self-reported nature of study conduct, but the magnitude of the reported prevalence and

349 working days lost cannot be ignored.

350

351 In our explanatory model, the presence of the COVID-19 composite endpoint was less likely in

352 current tobacco smokers which persisted when adjustments for comorbidities were removed

353 from the model. Petrilli et al.(Petrilli et al., 2020) noted a similar protective effect against

354 hospitalisation from COVID-19 amongst smokers in the general population, though it was

355 reasoned that this could be due to absence of data. In a separate observational study, Williamson

356 et al.(Williamson et al., 2020) noted that being a current smoker was associated with a lower risk

357 of mortality after adjusting for comorbidities, which were largely driven by the adjustment for

358 chronic respiratory disease and may also explain the mechanism behind our findings with

359 smoking in this study. Nicotine has been posited as a potential treatment option for COVID-19

360 patients.(Farsalinos et al., 2020) In contrast, smoking has been implicated in progression of

361 COVID-19 infection, with recommendations for current smokers to engage with

362 cessation.(World Health Organization; Zyl-Smit, Richards \& Leone, 2020) Based on our survey

363 data collection method, we may have missed a cohort of healthcare workers who smoke and been

364 affected with more severe COVID-19 and who were thus, unable to participate in the survey.

365

366 Our data did not suggest any difference between White and BAME groups within the healthcare

367 workers population for developing the COVID-19 composite endpoint, after adjusting for 
368 comorbidities (including obesity). However, amongst the hospitalised group, there was a higher

369 proportion of BAME healthcare workers compared with the total sampled population (40.8\% vs.

$37023.7 \%$ ), particularly 'Asian or Asian British', and 'Black, African, Black British or Caribbean'.

371 Increased focus on the BAME community has resulted from findings of more severe COVID-19

372 infection amongst individuals of BAME origin.(Intensive Care National Audit \& Research

373 Centre, 2020; Aldridge et al., 2020; Kursumovic, Lennane \& Cook, 2020) PHE have previously

374 reported on the disparities in risks and outcomes for COVID-19 infection, identifying a higher

375 prevalence of positive tests for SARS-CoV-2 and more severe disease amongst BAME groups

376 within the UK, though the effects of occupation and comorbidities (including obesity) were

377 unaccounted for.(Public Health England, 2020a,b) Thus, despite our finding of similar risks in

378 terms of developing the COVID-19 composite endpoint (and, therefore, possible COVID-19

379 infection), it remains the case that healthcare workers from BAME origins may be at risk of

380 more severe disease and death.

381

382 We identified use of public transport to get to work as an independent risk factor for COVID-19

383 infection. Previous data in China has shown an association between use of public transport and

384 spread of COVID-19.(Zheng et al., 2020; Zhao et al., 2020) Prior to the lockdown decision in the

385 UK on the $23^{\text {rd }}$ of March,(Dunn et al.) public transport was still operational. After this date, key

386 workers were still allowed to utilise public transport, which included healthcare workers. Due to

387 the presumed method of COVID-19 transmission,(Public Health England) the close proximity of

388 individuals using public transport was likely a factor in increasing risk. However, there are many

389 other possible confounding factors that impact on this finding which would be difficult to control

390 for. 
392 Adequate training and correct use of PPE (particularly during donning and doffing) are important

393 in reducing the risk of transmission of respiratory infectious disease from patient to healthcare

394 workers(Verbeek et al., 2020; Cook, 2020) and this was reflected in our results. This may also

395 explain our finding that healthcare workers exposed to regular AGPs in suspected or confirmed

396 COVD-19 patients were less likely to have the presence of the primary endpoint. Given the

397 importance of PPE use to protect against viral transmission,(Verbeek et al., 2020; Liu et al.,

398 2020; Tabah et al., 2020) it is unsurprising that participants who lacked access to PPE items, and

399 those who were more frequently exposed to suspected or confirmed cases of COVID-19 without

400 adequate PPE had a higher risk of the presence of the COVID-19 composite endpoint. That

401 nearly a quarter of UK healthcare workers reported being in such a situation is notable.

402

403 Strengths and Limitations

404 Strengths of our study include a relatively large sample size and the inclusion of healthcare

405 workers from all backgrounds and work environments to facilitate risk comparisons using a

406 standardised survey. We captured granular information that has otherwise been poorly reported

407 in prevalence studies in healthcare workers. For example, medical history and details regarding

408 the use, or lack thereof, of PPE have not been elsewhere reported. We did not limit our

409 recruitment to primary or secondary care; further, our sample demographics are comparable to

410 the overall population characteristics of all healthcare workers across the NHS, which show a

411 similar distribution by sex and ethnicity,(GOV.UK; The King's Fund) and was well-represented

412 by a wide range of healthcare worker roles. Our findings are thus likely to be generalisable

413 across the UK.

Peer] reviewing PDF | (2020:10:54534:1:2:NEW 26 Dec 2020) 
415 Several limitations need to be addressed. First, data were gathered using a survey-based approach which risks selection and recall bias. We also could not capture data from healthcare

417 workers who died from COVID-19 infection, or those who were too ill to respond. However, our 418 methodology allowed us to rapidly capture both objective and subjective granular data from a

419 large number of participants. Second, we were unable to determine a denominator to quantify a 420 response rate for this observational study. Third, the use of a composite outcome to detect 421 suspected or confirmed COVID-19 infection in healthcare workers may have resulted in an 422 overestimation of prevalence. However, this definition is in keeping with that used in other 423 studies(El-Boghdadly et al., 2020) and internationally.(CDC, 2020) Availability of testing for

424 healthcare workers was also limited during early phases of the pandemic, thus clinical diagnoses 425 were often relied upon. On the other hand, data have estimated that $7 \%$ of healthcare workers are 426 asymptomatic seroconverters,(Office for National Statistics; Treibel et al., 2020) and thus our 427 data could potentially represent an underestimation of COVID-19 transmission during the height 428 of the pandemic in UK. Fourth, we sought some subjective data, although this was a pragmatic 429 decision to maximise detail in responses. Fifth, several changes to national guidance and policies were made throughout the study period(Dunn et al.) which may confound responses regarding 431 PPE. Finally, all data herein are subjective and represent hypothesis-generating associations in 432 the responding participants; further objective analyses are required.

\section{${ }_{433}$ Conclusions}

434 We found a reported prevalence estimate of suspected or confirmed COVID-19 infection of 435 nearly a third, based on a COVID-19 composite endpoint, amongst healthcare workers within the 
436 UK. As a consequence of self-isolation, between 11,000 to 21,000 days of clinical service was

437 lost which could have been mitigated by more robust SARS-CoV-2 testing strategies. There

438 remain ongoing reports of difficulties in the availability of COVID-19 testing, of laboratories

439 struggling to meet with demand, and that the requirement for testing greatly exceeds current

440 capacity which needs to be urgently addressed. We also present several risk factors associated

441 with reporting of this endpoint, lack of PPE being an important consideration. Policymakers need

442 to ensure adequate PPE supplies to all healthcare workers in preparation for a potential surge in

443 COVID-19 cases and that accessible, rapid, accurate testing strategies are available to improve

444 healthcare workforce planning and continuation.

\section{${ }_{445}$ Acknowledgements}

446 The authors would like to thank all of the 6260 healthcare workers who participated in the

447 healthcareCOVID study. In addition, we would like to thank Steve Palmer and Knack

448 (Pennsylvania, USA) for providing assistance with the web-based software, database and server

449 space used for the healthcareCOVID study.

\section{References}

451 Aldridge RW, Lewer D, Katikireddi SV, Mathur R, Pathak N, Burns R, Fragaszy EB, Johnson

452

453

454

455
AM, Devakumar D, Abubakar I, Hayward A. 2020. Black, Asian and Minority Ethnic groups in England are at increased risk of death from COVID-19: indirect standardisation of NHS mortality data. Wellcome Open Research 5:88. DOI:

10.12688/wellcomeopenres.15922.1. 
456 Amnesty Internaional UK.UK among highest COVID-19 health worker deaths in the world.

457

458

459

460

461

462

463

464

465

466

467

468

469

470

471

472

473

474

475

476
Available at https://www.amnesty.org.uk/press-releases/uk-among-highest-covid-19-

health-worker-deaths-world (accessed July 20, 2020).

CDC. 2020.Coronavirus Disease 2019 (COVID-19) in the U.S. Available at https://www.cdc.gov/coronavirus/2019-ncov/cases-updates/cases-in-us.html (accessed October 11, 2020).

Cook TM. 2020. Personal protective equipment during the coronavirus disease (COVID) 2019 pandemic - a narrative review. Anaesthesia. DOI: 10.1111/anae.15071.

Dunn P, Allen L, Cameron G, Alderwick H.COVID-19 policy tracker. Available at https://www.health.org.uk/news-and-comment/charts-and-infographics/covid-19-policytracker (accessed June 7, 2020).

El-Boghdadly K, Wong DJN, Owen R, Neuman MD, Pocock S, Carlisle JB, Johnstone C, Andruszkiewicz P, Baker PA, Biccard BM, Bryson GL, Chan MTV, Cheng MH, Chin KJ, Coburn M, Jonsson Fagerlund M, Myatra SN, Myles PS, O’Sullivan E, Pasin L, Shamim F, van Klei WA, Ahmad I. 2020. Risks to healthcare workers following tracheal intubation of patients with COVID-19: a prospective international multicentre cohort study. Anaesthesia. DOI: 10.1111/anae.15170.

Farsalinos K, Niaura R, Le Houezec J, Barbouni A, Tsatsakis A, Kouretas D, Vantarakis A, Poulas K. 2020. Editorial: Nicotine and SARS-CoV-2: COVID-19 may be a disease of the nicotinic cholinergic system. Toxicology Reports 7:658-663. DOI:

10.1016/j.toxrep.2020.04.012. 
477 GOV.UK.NHS workforce. Available at https://www.ethnicity-facts-

478 figures.service.gov.uk/workforce-and-business/workforce-diversity/nhs-workforce/latest

$479 \quad$ (accessed December 9, 2020).

480 Heneghan C, Brassey J, Jefferson T. 2020.SARS-CoV-2 viral load and the severity of COVID-

481

482

483

484

485

486

487

488

489

490

491

492

493

494

495

496

497

498

19. Available at https://www.cebm.net/covid-19/sars-cov-2-viral-load-and-the-severityof-covid-19/(accessed April 8, 2020).

Heneghan C, Oke J, Jefferson T. 2020.COVID-19 How many Healthcare workers are infected? Available at https://www.cebm.net/covid-19/covid-19-how-many-healthcare-workers-areinfected/(accessed June 19, 2020).

Hunter E, Price DA, Murphy E, Loeff IS van der, Baker KF, Lendrem D, Lendrem C, Schmid ML, Pareja-Cebrian L, Welch A, Payne BAI, Duncan CJA. 2020. First experience of COVID-19 screening of health-care workers in England. The Lancet 0. DOI: 10.1016/S0140-6736(20)30970-3.

Intensive Care National Audit \& Research Centre. 2020. ICNARC report on COVID-19 in critical care (ICNARC).

Keeley AJ, Evans C, Colton H, Ankcorn M, Cope A, State A, Bennett T, Giri P, de Silva TI, Raza M. 2020. Roll-out of SARS-CoV-2 testing for healthcare workers at a large NHS Foundation Trust in the United Kingdom, March 2020. Euro Surveillance: Bulletin Europeen Sur Les Maladies Transmissibles = European Communicable Disease Bulletin 25. DOI: $10.2807 / 1560-7917 . E S .2020 .25 .14 .2000433$.

Kursumovic E, Lennane S, Cook TM. 2020. Deaths in healthcare workers due to COVID-19: the need for robust data and analysis. Anaesthesia. DOI: 10.1111/anae.15116. 
499

500

501

502

503

504

505

506

507

508

509

510

511

512

513

514

515

516

517

518

519

520

Liu M, Cheng S-Z, Xu K-W, Yang Y, Zhu Q-T, Zhang H, Yang D-Y, Cheng S-Y, Xiao H, Wang J-W, Yao H-R, Cong Y-T, Zhou Y-Q, Peng S, Kuang M, Hou F-F, Cheng KK, Xiao H-P. 2020. Use of personal protective equipment against coronavirus disease 2019 by healthcare professionals in Wuhan, China: cross sectional study. $B M J 369$. DOI: 10.1136/bmj.m2195.

Nguyen LH, Drew DA, Graham MS, Joshi AD, Guo C-G, Ma W, Mehta RS, Warner ET, Sikavi DR, Lo C-H, Kwon S, Song M, Mucci LA, Stampfer MJ, Willett WC, Eliassen AH, Hart JE, Chavarro JE, Rich-Edwards JW, Davies R, Capdevila J, Lee KA, Lochlainn MN, Varsavsky T, Sudre CH, Cardoso MJ, Wolf J, Spector TD, Ourselin S, Steves CJ, Chan AT, Albert CM, Andreotti G, Bala B, Balasubramanian BA, Beane-Freeman LE, Brownstein JS, Bruinsma FJ, Coresh J, Costa R, Cowan AN, Deka A, Deming-Halverson SL, Martinez ME, Ernst ME, Figueiredo JC, Fortuna P, Franks PW, Freeman LB, Gardner CD, Ghobrial IM, Haiman CA, Hall JE, Kang JH, Kirpach B, Koenen KC, Kubzansky LD, James V. Lacey J, Marchand LL, Lin X, Lutsey P, Marinac CR, Martinez ME, Milne RL, Murray AM, Nash D, Palmer JR, Patel AV, Pierce E, Robertson MM, Rosenberg L, Sandler DP, Schurman SH, Sewalk K, Sharma SV, Sidey-Gibbons CJ, Slevin L, Smoller JW, Steves CJ, Tiirikainen MI, Weiss ST, Wilkens LR, Zhang F. 2020. Risk of COVID-19 among front-line health-care workers and the general community: a prospective cohort study. The Lancet Public Health 0. DOI: 10.1016/S2468-2667(20)30164-X.

Office for National Statistics.Coronavirus (COVID-19) Infection Survey pilot. Available at https://www.ons.gov.uk/peoplepopulationandcommunity/healthandsocialcare/conditionsa 
521

522

523

524

525

526

527

528

529

530

531

532

533

534

535

536

537

538

539

540

541

542

543

nddiseases/bulletins/coronaviruscovid19infectionsurveypilot/28may2020 (accessed May $30,2020)$.

Petrilli CM, Jones SA, Yang J, Rajagopalan H, O’Donnell L, Chernyak Y, Tobin KA, Cerfolio RJ, Francois F, Horwitz LI. 2020. Factors associated with hospital admission and critical illness among 5279 people with coronavirus disease 2019 in New York City: prospective cohort study. BMJ 369. DOI: 10.1136/bmj.m1966.

Pollán M, Pérez-Gómez B, Pastor-Barriuso R, Oteo J, Hernán MA, Pérez-Olmeda M, Sanmartín JL, Fernández-García A, Cruz I, Larrea NF de, Molina M, Rodríguez-Cabrera F, Martín M, Merino-Amador P, Paniagua JL, Muñoz-Montalvo JF, Blanco F, Yotti R, Blanco F, Fernández RG, Martín M, Navarro SM, Molina M, Muñoz-Montalvo JF, Hernández MS, Sanmartín JL, Cuenca-Estrella M, Yotti R, Paniagua JL, Larrea NF de, FernándezNavarro P, Pastor-Barriuso R, Pérez-Gómez B, Pollán M, Avellón A, Fedele G, Fernández-García A, Iglesias JO, Olmeda MTP, Cruz I, Martinez MEF, RodríguezCabrera FD, Hernán MA, Fernández SP, Aguirre JMR, Marí JMN, Borrás BP, Jiménez ABP, Rodríguez-Iglesias M, Gascón AMC, Alcaine MLL, Suárez ID, Álvarez OS, Pérez MR, Sanchís MC, Gomila CJV, Saladrigas LC, Fernández AH, Oliver A, Feliciano EC, Quintana MNG, Fernández JMB, Betancor MAH, Febles MH, Martín LM, López L-ML, Miota TU, Población IDB, Pérez MSC, Fernández MNV, Enríquez TM, Arranz MV, González MD-G, Fernández-Natal I, Lobón GM, Bellido JLM, Ciruela P, Casals AM i, Botías MD, Maeso MAM, Campo DP del, Castro AF de, Ramírez RL, Retamosa MFE, González MR, Lobeiras MSB, Losada AF, Aguilera A, Bou G, Caro Y, Marauri N, Blanco LMS, González I del C, Pascual MH, Fernández RA, Merino-Amador P, Castro NC, Lizcano AT, Almagro CR, Hernández MS, Elizaga NA, Sanz ME, Baquedano CE, 
544

545

546

547

548

549

550

551

552

553

554

555

556

557

558

559

560

561

562

563

564

565

566

Bascaran AB, Tamayo SI, Otazua LE, Benarroch RB, Flores JL, Villa AV de la. 2020.

Prevalence of SARS-CoV-2 in Spain (ENE-COVID): a nationwide, population-based seroepidemiological study. The Lancet 0. DOI: 10.1016/S0140-6736(20)31483-5.

Public Health England. 2020a.COVID-19: review of disparities in risks and outcomes. Available at https://www.gov.uk/government/publications/covid-19-review-of-disparities-in-risksand-outcomes (accessed June 8, 2020).

Public Health England. 2020b.COVID-19: understanding the impact on BAME communities. Available at https://www.gov.uk/government/publications/covid-19-understanding-theimpact-on-bame-communities (accessed June 22, 2020).

Public Health England.COVID-19 personal protective equipment (PPE). Available at https://www.gov.uk/government/publications/wuhan-novel-coronavirus-infectionprevention-and-control/covid-19-personal-protective-equipment-ppe (accessed June 1, 2020a).

Public Health England.Transmission characteristics and principles of infection prevention and control. Available at https://www.gov.uk/government/publications/wuhan-novelcoronavirus-infection-prevention-and-control/transmission-characteristics-andprinciples-of-infection-prevention-and-control (accessed June 9, 2020b).

Reisner SL, Biello K, Rosenberger JG, Austin SB, Haneuse S, Perez-Brumer A, Novak DS, Mimiaga MJ. 2014. Using a Two-Step Method to Measure Transgender Identity in Latin America/the Caribbean, Portugal, and Spain. Archives of sexual behavior 43:1503-1514. DOI: $10.1007 / \mathrm{s} 10508-014-0314-2$.

Shah ASV, Wood R, Gribben C, Caldwell D, Bishop J, Weir A, Kennedy S, Reid M, SmithPalmer A, Goldberg D, McMenamin J, Fischbacher C, Robertson C, Hutchinson S, 
567

568

569

570

571

572

573

574

575

576

577

578

579

580

581

582

583

584

585

586

587

588

McKeigue P, Colhoun H, McAllister DA. 2020. Risk of hospital admission with coronavirus disease 2019 in healthcare workers and their households: nationwide linkage cohort study. BMJ 371. DOI: 10.1136/bmj.m3582.

Shields A, Faustini SE, Perez-Toledo M, Jossi S, Aldera E, Allen JD, Al-Taei S, Backhouse C, Bosworth A, Dunbar LA, Ebanks D, Emmanuel B, Garvey M, Gray J, Kidd IM, McGinnell G, McLoughlin DE, Morley G, O’Neill J, Papakonstantinou D, Pickles O, Poxon C, Richter M, Walker EM, Wanigasooriya K, Watanabe Y, Whalley C, Zielinska AE, Crispin M, Wraith DC, Beggs AD, Cunningham AF, Drayson MT, Richter AG. 2020. SARS-CoV-2 seroprevalence and asymptomatic viral carriage in healthcare workers: a cross-sectional study. Thorax. DOI: 10.1136/thoraxjnl-2020-215414.

Spiel K, Haimson OL, Lottridge D. 2019. How to do better with gender on surveys: a guide for HCI researchers. Interactions 26:62-65. DOI: 10.1145/3338283.

STROBE Group.STROBE Statement: Available checklists. Available at https://www.strobestatement.org/index.php?id=available-checklists (accessed July 5, 2020).

Tabah A, Ramanan M, Laupland KB, Buetti N, Cortegiani A, Mellinghoff J, Morris AC, Camporota L, Zappella N, Elhadi M, Povoa P, Amrein K, Vidal G, Derde L, Bassetti M, Francois G, Kai NSSIYAN, De Waele JJ. 2020. Personal protective equipment and intensive care unit healthcare worker safety in the COVID-19 era (PPE-SAFE): An international survey. Journal of Critical Care. DOI: 10.1016/j.jcrc.2020.06.005.

The King's Fund.Overview of the health and social care workforce. Available at https://www.kingsfund.org.uk/projects/time-think-differently/trends-workforce-overview (accessed December 9, 2020). 
589 The Lancet. 2020. COVID-19: protecting health-care workers. The Lancet 395:922. DOI:

590 10.1016/S0140-6736(20)30644-9.

591 Treibel TA, Manisty C, Burton M, McKnight Á, Lambourne J, Augusto JB, Couto-Parada X, 592 Cutino-Moguel T, Noursadeghi M, Moon JC. 2020. COVID-19: PCR screening of 593 asymptomatic health-care workers at London hospital. The Lancet 395:1608-1610. DOI: $10.1016 / \mathrm{S} 0140-6736(20) 31100-4$.

595

596

597

598

599

600

601

602

603

604

605

606

607

608

609

610

611

Verbeek JH, Rajamaki B, Ijaz S, Sauni R, Toomey E, Blackwood B, Tikka C, Ruotsalainen JH, Kilinc Balci FS. 2020. Personal protective equipment for preventing highly infectious diseases due to exposure to contaminated body fluids in healthcare staff. The Cochrane Database of Systematic Reviews 5:CD011621. DOI: 10.1002/14651858.CD011621.pub5.

Williamson EJ, Walker AJ, Bhaskaran K, Bacon S, Bates C, Morton CE, Curtis HJ, Mehrkar A, Evans D, Inglesby P, Cockburn J, McDonald HI, MacKenna B, Tomlinson L, Douglas IJ, Rentsch CT, Mathur R, Wong AYS, Grieve R, Harrison D, Forbes H, Schultze A, Croker R, Parry J, Hester F, Harper S, Perera R, Evans SJW, Smeeth L, Goldacre B. 2020. Factors associated with COVID-19-related death using OpenSAFELY. Nature 584:430436. DOI: $10.1038 / \mathrm{s} 41586-020-2521-4$.

Wilson NM, Norton A, Young FP, Collins DW. 2020. Airborne transmission of severe acute respiratory syndrome coronavirus-2 to healthcare workers: a narrative review. Anaesthesia. DOI: 10.1111/anae.15093.

World Health Organization.WHO COVID-19 Dashboard. Available at https:/who.sprinklr.com/ (accessed October 11, 2020a).

World Health Organization.Rational use of personal protective equipment for coronavirus disease (COVID-19) and considerations during severe shortages. Available at 
612

613

614

615

616

617

618

619

620

621

622

623

624

625

626

627

https://www.who.int/publications-detail/rational-use-of-personal-protective-equipmentfor-coronavirus-disease-(covid-19)-and-considerations-during-severe-shortages (accessed June 1, 2020b).

World Health Organization.Information note on COVID-19 and NCDs. Available at https://www.who.int/who-documents-detail-redirect/covid-19-and-ncds (accessed June 9, 2020c).

Zhao S, Zhuang Z, Ran J, Lin J, Yang G, Yang L, He D. 2020. The association between domestic train transportation and novel coronavirus (2019-nCoV) outbreak in China from 2019 to 2020: A data-driven correlational report. Travel Medicine and Infectious Disease 33:101568. DOI: 10.1016/j.tmaid.2020.101568.

Zheng R, Xu Y, Wang W, Ning G, Bi Y. 2020. Spatial transmission of COVID-19 via public and private transportation in China. Travel Medicine and Infectious Disease 34:101626. DOI: 10.1016/j.tmaid.2020.101626.

Zyl-Smit RN van, Richards G, Leone FT. 2020. Tobacco smoking and COVID-19 infection. The Lancet Respiratory Medicine 0. DOI: 10.1016/S2213-2600(20)30239-3. 
Figure 1

STROBE flowchart for analysis of survey responses.

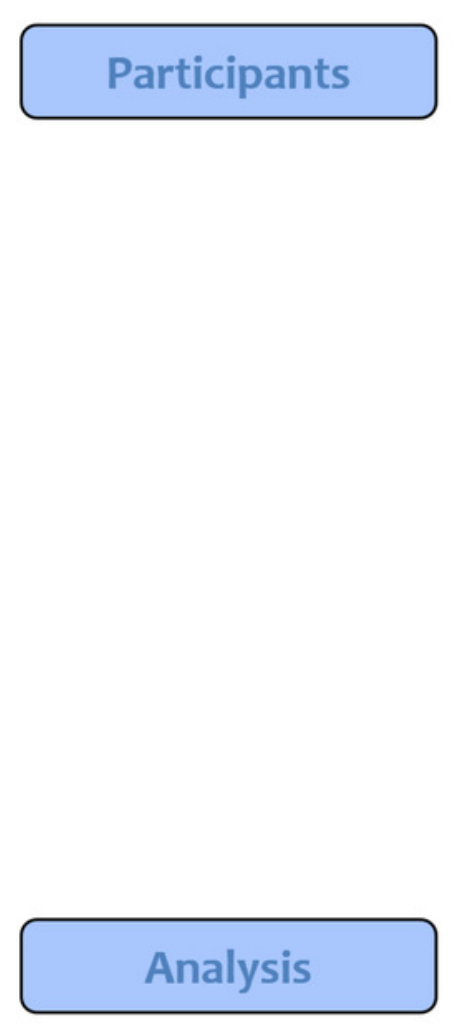

$$
\text { Survey responses received }(n=6,260)
$$

Excluded $(n=108)$

- Used for convenience pilot sample $(n=93)$

- Did not meet inclusion criteria $(n=1)$

- After "Intersex" option removed for 'Sex assigned at birth' question $(\mathrm{n}=2)$

- Erroneous free-text entry in 'Age' question $(n=1)$

- Conflicts in reporting of comorbidities $(\mathrm{n}=9)$

- Conflicts in reporting of symptoms during self-isolation $(n=2)$

Included for analysis $(n=6,152)$ 
Figure 2

Bar graph of main location of work grouped by all participants ( $n=6152$ ) and participants where the COVID-19 composite endpoint was reported $(n=1806)$.

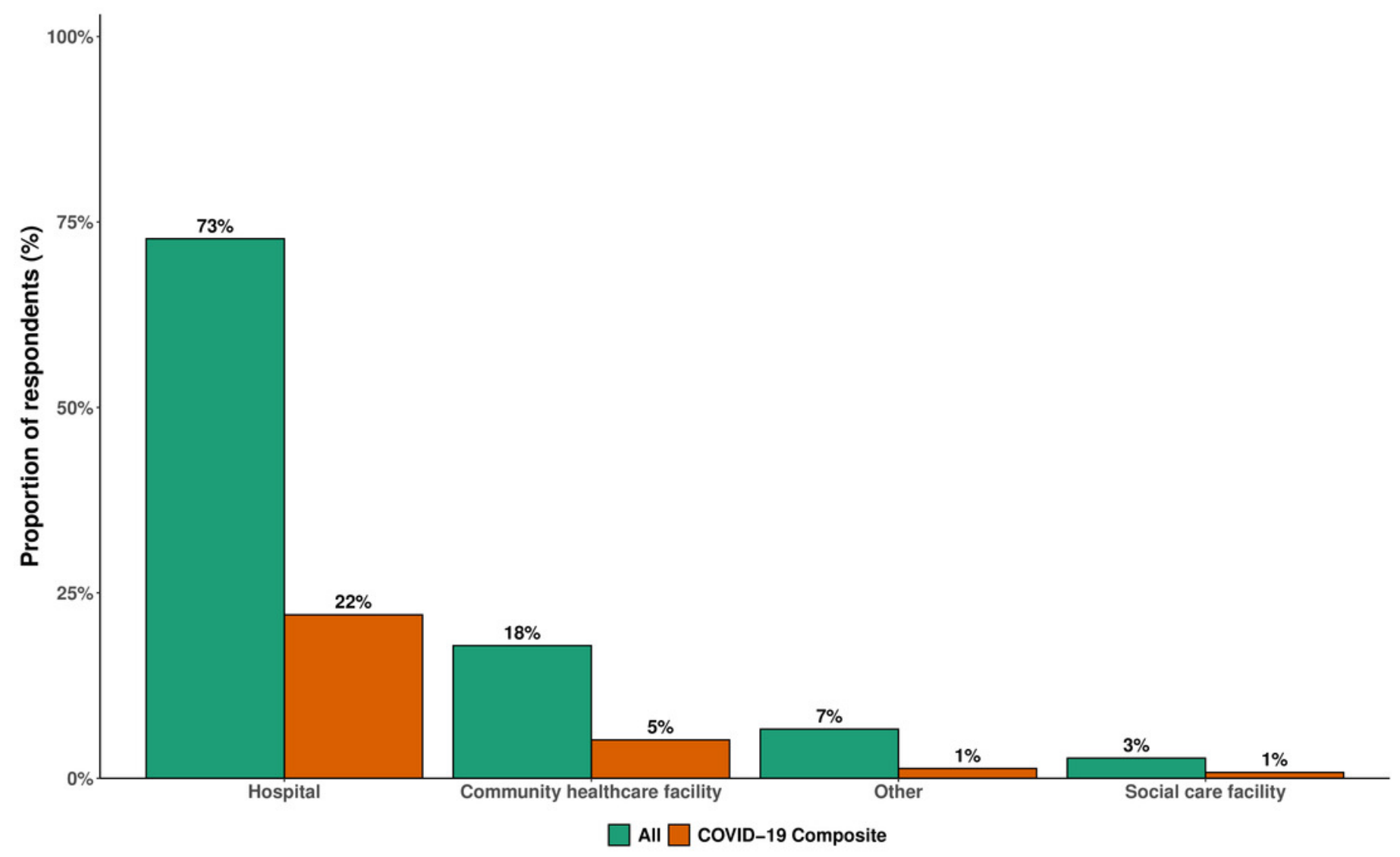




\section{Figure 3}

PPE items that participants lacked access to of those who have been in a situation where they lacked access during clinical contact with suspected/confirmed COVID-19 patients $(n=1382)$.

Abbreviations: PPE $=$ Personal Protective Equipment; PAPR $=$ Powered air-purifying respirator.

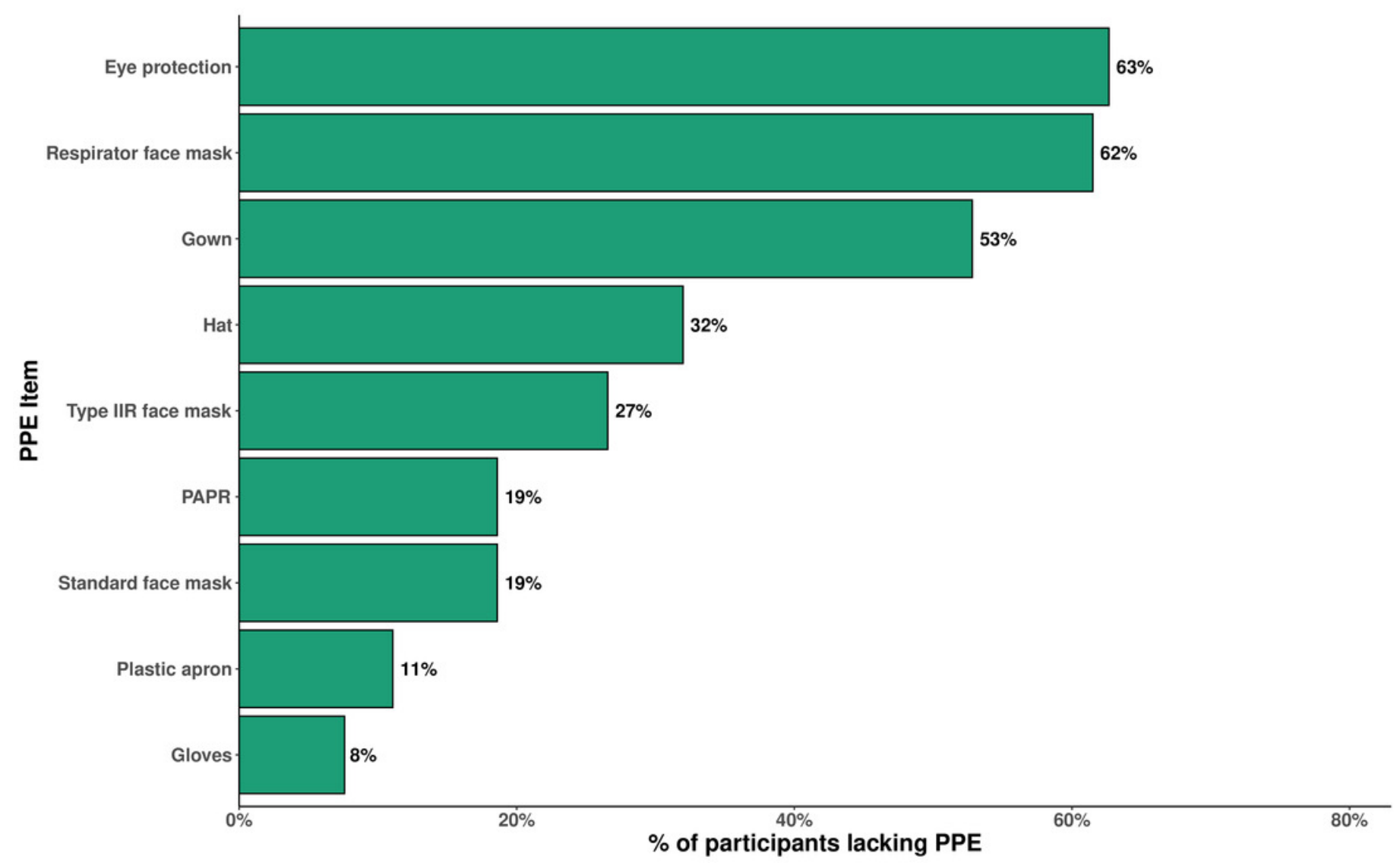




\section{Table 1 (on next page)}

Summary of participant characteristics, stratified by COVID-19 outcome.

$\mathrm{n}(\%)$ or mean (SD)

${ }^{1}$ All participants

${ }^{2}$ Participants with the presence of the COVID-19 composite endpoint

${ }^{3}$ Participants who self-isolated due to symptoms and/or testing positive for SARS-CoV-2

${ }^{4}$ Participants who were hospitalised due to suspected/confirmed COVID-19

${ }^{5}$ Participants who have tested positive for SARS-CoV-2 


\begin{tabular}{|c|c|c|c|c|c|}
\hline & $\begin{array}{c}\text { All }^{1} \\
(n=6152)\end{array}$ & $\begin{array}{l}\text { COVID-19 } \\
\text { Composite } \\
\text { Endpoint }^{2} \\
(n=1806)\end{array}$ & $\begin{array}{l}\text { Self-isolated }^{3} \\
\quad(n=1776)\end{array}$ & $\begin{array}{l}\text { Hospitalised }^{4} \\
\quad(n=49)\end{array}$ & $\begin{array}{c}\text { Lab- } \\
\text { confirmed } \\
\text { COVID-195 } \\
(n=459)\end{array}$ \\
\hline \multicolumn{6}{|l|}{ Age } \\
\hline years, mean (SD) & $43.2(10.6)$ & $41.9(10.2)$ & $41.9(10.2)$ & $42.6(11.9)$ & $42.5(10.2)$ \\
\hline \multicolumn{6}{|l|}{ Sex } \\
\hline Female & $4,789(77.8 \%)$ & $1,416(78.4 \%)$ & $1,397(78.7 \%)$ & $32(65.3 \%)$ & $333(72.5 \%)$ \\
\hline Male & $1,363(22.2 \%)$ & $390(21.6 \%)$ & $379(21.3 \%)$ & $17(34.7 \%)$ & $126(27.5 \%)$ \\
\hline \multicolumn{6}{|l|}{ Ethnic group } \\
\hline Asian or Asian British & $846(13.8 \%)$ & $267(14.8 \%)$ & $259(14.6 \%)$ & $12(24.5 \%)$ & $74(16.1 \%)$ \\
\hline Black, African, Black British or Caribbean & $299(4.9 \%)$ & $100(5.5 \%)$ & $98(5.5 \%)$ & $5(10.2 \%)$ & $23(5.0 \%)$ \\
\hline Mixed or multiple ethnic groups & $149(2.4 \%)$ & $48(2.7 \%)$ & $48(2.7 \%)$ & $2(4.1 \%)$ & $14(3.1 \%)$ \\
\hline White & $4,667(75.9 \%)$ & $1,330(73.6 \%)$ & $1,313(73.9 \%)$ & $29(59.2 \%)$ & $331(72.1 \%)$ \\
\hline Another ethnic group & $162(2.6 \%)$ & $53(2.9 \%)$ & $50(2.8 \%)$ & $1(2.0 \%)$ & $16(3.5 \%)$ \\
\hline Prefer not to say & $29(0.5 \%)$ & $8(0.4 \%)$ & $8(0.5 \%)$ & $0(0.0 \%)$ & $1(0.2 \%)$ \\
\hline \multicolumn{6}{|l|}{ Household - Persons } \\
\hline Lives alone & $675(11.0 \%)$ & $205(11.4 \%)$ & $200(11.3 \%)$ & $6(12.2 \%)$ & $49(10.7 \%)$ \\
\hline Lives with 1 or more persons & $5,477(89.0 \%)$ & $1,601(88.6 \%)$ & $1,576(88.7 \%)$ & $43(87.8 \%)$ & $410(89.3 \%)$ \\
\hline \multicolumn{6}{|l|}{ Household - Children } \\
\hline No children & $2,338(38.0 \%)$ & $664(36.8 \%)$ & $654(36.8 \%)$ & $25(51.0 \%)$ & $168(36.6 \%)$ \\
\hline Has children & $3,139(51.0 \%)$ & $937(51.9 \%)$ & $922(51.9 \%)$ & $18(36.7 \%)$ & $242(52.7 \%)$ \\
\hline \multicolumn{6}{|l|}{ Comorbidities } \\
\hline Hypertension & $537(8.7 \%)$ & $158(8.7 \%)$ & $157(8.8 \%)$ & $6(12.2 \%)$ & $35(7.6 \%)$ \\
\hline Diabetes & $188(3.1 \%)$ & $57(3.2 \%)$ & $54(3.0 \%)$ & $6(12.2 \%)$ & $17(3.7 \%)$ \\
\hline Cancer & $78(1.3 \%)$ & $28(1.6 \%)$ & $28(1.6 \%)$ & $0(0.0 \%)$ & $5(1.1 \%)$ \\
\hline Heart disease & $76(1.2 \%)$ & $23(1.3 \%)$ & $23(1.3 \%)$ & $0(0.0 \%)$ & $4(0.9 \%)$ \\
\hline Immunosuppression & $109(1.8 \%)$ & $27(1.5 \%)$ & $27(1.5 \%)$ & $2(4.1 \%)$ & $2(0.4 \%)$ \\
\hline Respiratory disease & $569(9.2 \%)$ & $198(11.0 \%)$ & $192(10.8 \%)$ & $15(30.6 \%)$ & $49(10.7 \%)$ \\
\hline Renal disease & $35(0.6 \%)$ & $10(0.6 \%)$ & $10(0.6 \%)$ & $2(4.1 \%)$ & $3(0.7 \%)$ \\
\hline Liver disease & $30(0.5 \%)$ & $10(0.6 \%)$ & $10(0.6 \%)$ & $0(0.0 \%)$ & $2(0.4 \%)$ \\
\hline Neurological disease & $64(1.0 \%)$ & $18(1.0 \%)$ & $18(1.0 \%)$ & $0(0.0 \%)$ & $3(0.7 \%)$ \\
\hline Obesity & $692(11.2 \%)$ & $236(13.1 \%)$ & $234(13.2 \%)$ & $8(16.3 \%)$ & $47(10.2 \%)$ \\
\hline None of the above & $4,200(68.3 \%)$ & $1,192(66.0 \%)$ & $1,173(66.0 \%)$ & $23(46.9 \%)$ & $317(69.1 \%)$ \\
\hline Prefer not to say & $97(1.6 \%)$ & $26(1.4 \%)$ & $25(1.4 \%)$ & $0(0.0 \%)$ & $8(1.7 \%)$ \\
\hline \multicolumn{6}{|l|}{ Tobacco smoking status } \\
\hline Current or Ex-smoker within 1 year & $551(9.0 \%)$ & $142(7.9 \%)$ & $139(7.8 \%)$ & $3(6.1 \%)$ & $27(5.9 \%)$ \\
\hline Ex-smoker $>1$ year & $1,221(19.8 \%)$ & $361(20.0 \%)$ & $357(20.1 \%)$ & $7(14.3 \%)$ & $96(20.9 \%)$ \\
\hline Never smoked & $4,305(70.0 \%)$ & $1,279(70.8 \%)$ & $1,258(70.8 \%)$ & $38(77.6 \%)$ & $327(71.2 \%)$ \\
\hline Prefer not to say & $75(1.2 \%)$ & $24(1.3 \%)$ & $22(1.2 \%)$ & $1(2.0 \%)$ & $9(2.0 \%)$ \\
\hline
\end{tabular}




\section{Table 2 (on next page)}

Variables and association with the composite endpoint.

Univariate and multivariate odds ratio (OR), 95\% confidence intervals $(95 \% \mathrm{Cl})$.

Akaike information criterion (AIC) for above model $=7233.562$; AIC for null model $=7449.750$. Area Under the Receiver Operating Characteristics (AUROC) for above model $=0.63$; AUROC for null model $=0.50$.

$* p$-value $<0.05$ for multivariable model.

Abbreviations: Ref $=$ Reference value, BAME $=$ Black, Asian and Minority Ethnic, AGP $=$ Aerosol-Generating Procedures, PPE $=$ Personal Protective Equipment. 


\begin{tabular}{|c|c|c|c|c|}
\hline & $\begin{array}{l}\text { Univariable } \\
\text { OR }(95 \% \mathrm{Cl})\end{array}$ & $p$-value & $\begin{array}{c}\text { Multivariable } \\
\text { adjusted OR }(95 \% \mathrm{Cl})\end{array}$ & $p$-value \\
\hline \multicolumn{5}{|l|}{ Age } \\
\hline Age (per year)* & $0.98(0.97-0.99)$ & $<0.001$ & $0.98(0.98-0.99)$ & $<0.001$ \\
\hline \multicolumn{5}{|l|}{ Sex } \\
\hline Female & Ref & Ref & Ref & Ref \\
\hline Male & $0.95(0.84-1.09)$ & 0.516 & $0.92(0.79-1.06)$ & 0.248 \\
\hline \multicolumn{5}{|l|}{ Ethnicity } \\
\hline White & Ref & Ref & Ref & Ref \\
\hline$B A M E$ & $1.19(1.05-1.35)$ & 0.008 & $0.98(0.85-1.12)$ & 0.747 \\
\hline Prefer not to say & $0.96(0.42-2.16)$ & 1.000 & $0.91(0.36-2.06)$ & 0.825 \\
\hline \multicolumn{5}{|l|}{ Household - persons } \\
\hline Lives alone & Ref & Ref & Ref & Ref \\
\hline Lives with 1 or more persons; no children & $0.91(0.75-1.10)$ & 0.344 & $0.87(0.72-1.06)$ & 0.179 \\
\hline Lives with 1 or more persons; has children & $0.98(0.81-1.17)$ & 0.825 & $1.00(0.83-1.21)$ & 0.962 \\
\hline \multicolumn{5}{|l|}{ Comorbidities } \\
\hline Hypertension & $1.00(0.83-1.22)$ & 1.000 & $1.13(0.91-1.40)$ & 0.258 \\
\hline Diabetes & $1.05(0.76-1.44)$ & 0.831 & $1.00(0.71-1.39)$ & 0.986 \\
\hline Cancer* & $1.35(0.85-2.16)$ & 0.249 & $1.66(1.01-2.67)$ & 0.041 \\
\hline Heart disease & $1.04(0.64-1.71)$ & 0.962 & $1.18(0.69-1.96)$ & 0.535 \\
\hline Immunosuppression & $0.79(0.51-1.22)$ & 0.340 & $0.83(0.52-1.29)$ & 0.421 \\
\hline Respiratory disease* & $1.32(1.10-1.58)$ & 0.003 & $1.26(1.04-1.52)$ & 0.015 \\
\hline Renal disease & $0.96(0.46-2.01)$ & 1.000 & $1.08(0.49-2.24)$ & 0.833 \\
\hline Liver disease & $1.20(0.56-2.58)$ & 0.781 & $1.18(0.51-2.53)$ & 0.686 \\
\hline Neurological disease & $0.94(0.54-1.63)$ & 0.937 & $0.88(0.49-1.52)$ & 0.662 \\
\hline Obesity* & $1.28(1.08-1.52)$ & 0.004 & $1.31(1.10-1.56)$ & 0.003 \\
\hline Prefer not to say & $0.88(0.56-1.38)$ & 0.657 & $0.94(0.58-1.48)$ & 0.779 \\
\hline \multicolumn{5}{|l|}{ Smoking status } \\
\hline Never smoked & Ref & Ref & Ref & Ref \\
\hline Current or Ex-smoker within 1 year* & $0.82(0.67-1.01)$ & 0.062 & $0.79(0.64-0.98)$ & 0.035 \\
\hline Ex-smoker (more than 1 year) & $0.99(0.86-1.14)$ & 0.951 & $1.09(0.94-1.27)$ & 0.238 \\
\hline Prefer not to say & $1.11(0.68-1.82)$ & 0.762 & $1.14(0.68-1.87)$ & 0.606 \\
\hline \multicolumn{5}{|l|}{ Country } \\
\hline England & Ref & Ref & Ref & Ref \\
\hline Northern Ireland* & $0.42(0.24-0.72)$ & 0.002 & $0.44(0.24-0.75)$ & 0.004 \\
\hline Scotland & $0.90(0.70-1.16)$ & 0.464 & $0.95(0.73-1.23)$ & 0.702 \\
\hline Wales & $0.86(0.63-1.17)$ & 0.379 & $1.17(0.84-1.62)$ & 0.344 \\
\hline \multicolumn{5}{|l|}{ Main healthcare facility } \\
\hline Hospital & Ref & Ref & Ref & Ref \\
\hline Community healthcare facility & $0.94(0.81-1.08)$ & 0.410 & $0.99(0.84-1.17)$ & 0.940 \\
\hline Social care facility & $0.95(0.67-1.33)$ & 0.819 & $1.17(0.81-1.68)$ & 0.399 \\
\hline Other & $0.58(0.45-0.74)$ & $<0.001$ & $0.82(0.61-1.08)$ & 0.168 \\
\hline \multicolumn{5}{|l|}{ Role group } \\
\hline Nurses, midwives and associated staff & Ref & Ref & Ref & Ref \\
\hline Allied health professionals* & $0.77(0.66-0.91)$ & 0.002 & $0.81(0.69-0.96)$ & 0.015 \\
\hline Dentists and dental staff* & $0.40(0.27-0.59)$ & $<0.001$ & $0.52(0.33-0.82)$ & 0.006 \\
\hline Doctors* & $1.16(1.02-1.33)$ & 0.025 & $1.2(1.04-1.39)$ & 0.015 \\
\hline Other & $0.84(0.68-1.03)$ & 0.102 & $0.99(0.78-1.24)$ & 0.915 \\
\hline Used public transport to travel to work* & $1.43(1.26-1.63)$ & $<0.001$ & $1.38(1.20-1.59)$ & $<0.001$ \\
\hline $\begin{array}{l}\text { Regular clinical contact with suspected or } \\
\text { confirmed COVID-19 patients* }\end{array}$ & $1.52(1.35-1.71)$ & $<0.001$ & $1.33(1.15-1.54)$ & $<0.001$ \\
\hline $\begin{array}{l}\text { Regular exposure to AGP(s) performed in } \\
\text { suspected or confirmed COVID-19 patients* }\end{array}$ & $0.97(0.86-1.08)$ & 0.582 & $0.81(0.71-0.93)$ & 0.004 \\
\hline Sufficient training in PPE use* & $0.79(0.70-0.89)$ & $<0.001$ & $0.85(0.75-0.98)$ & 0.023 \\
\hline $\begin{array}{l}\text { Lacked access to PPE items for clinical contact } \\
\text { with suspected or confirmed COVID-19 patients* }\end{array}$ & $1.74(1.53-1.97)$ & $<0.001$ & $1.28(1.09-1.51)$ & 0.002 \\
\hline
\end{tabular}




\begin{tabular}{|c|c|c|c|c|}
\hline Clinical contact without & & & & \\
\hline Never & Ref & Ref & Ref & Ref \\
\hline Rarely & $1.35(1.13-1.62)$ & 0.001 & $1.06(0.87-1.29)$ & 0.547 \\
\hline Sometimes* & $2.32(1.92-2.79)$ & $<0.001$ & $1.7(1.37-2.10)$ & $<0.001$ \\
\hline Often* & $2.56(1.83-3.58)$ & $<0.001$ & $1.84(1.28-2.63)$ & 0.001 \\
\hline Always* & $3.65(2.18-6.10)$ & $<0.001$ & $2.93(1.72-5.06)$ & $<0.001$ \\
\hline Reused disposable PPE & $1.21(1.07-1.37)$ & 0.002 & $0.98(0.86-1.13)$ & 0.821 \\
\hline Used improvised PPE* & $1.10(0.94-1.28)$ & 0.271 & $0.81(0.68-0.97)$ & 0.020 \\
\hline
\end{tabular}

1 